\title{
ELEKTROMANYETİK SUPAP İLE ÇALIŞAN BİR PNÖMATİK MOTOR İÇİN KONTROL ÜNİTESİ TASARIMI VE MOTOR PERFORMANSINA ETKİSİ
}

\author{
Haluk GÜNEŞ, M. Akif KUNT \\ Dumlupınar Üniversitesi, Tavşanlı Meslek Yüksek Okulu, Tavşanlı, Kütahya \\ haluk.gunes@dpu.edu.tr, mehmetakif.kunt@dpu.edu.tr
}

(Geliş/Received: 14.01.2013; Kabul/Accepted: 29.12.2015)

ÖZET

Bu çalışmada, 2 zamanlı içten yanmalı 49 cc'lik bir benzinli motor basınçlı hava ile çalışır hale getirilmiştir. Havanın silindir içerisine gönderilmesinde, bir elektromanyetik supaptan faydalanılmıştır. Elektromanyetik supabın kontrolü için Atmega8 mikrodenetleyicisinin kullanıldığı bir elektronik kontrol devresi tasarlanmış ve imal edilmiştir. Basınçlı hava, silindir içerisine farklı emme supap zamanlamalarında gönderilmiş ve motor performans değerleri karşılaştırılmıştır. Sonuçta elektronik kontrol devresi elektromanyetik supabı yaklaşık olarak 1600 1/min motor hızı için başarılı bir şekilde kumanda ettiği görülmüştür.

Anahtar Kelimeler: Pnömatik motor, elektromanyetik supap, mikrodenetleyici, atmel

\section{CONTROL UNIT DESIGN FOR A PNOMATIC ENGINE WORKING WITH AN ELECTROMAGNETIC VALVE AND ITS EFFECT ON PERFORMANCE OF THE ENGINE}

\begin{abstract}
ASTRACT
In this study a two stroke $49 \mathrm{cc}$ internal combustion gasoline engine was worked by compressed air. An electromagnetic valve was used to send air into cylinder. In order to control electromagnetic valve, an electronic control circuit was designed and produced using Altmega8 microcontroller. Compressed air was sent to cylinder in different intake valve timing and engine performance data were compared. As a result, it is seen that electronic control circuit controls magnetic valve successfully aproximately at $1600 \mathrm{rpm}$ speed.
\end{abstract}

Keywords: Pneumatic engine, electromagnetic valve, microcontroller, atmel

\section{GÍRISŞ (INTRODUCTION)}

İçten Yanmalı Motorlar (IYM), motosiklet ve taşıtlarda en çok kullanılan güç üretim sistemleridir. IYM'ler yakıttan aldığı kimyasal enerjiyi mekanik enerjiye dönüştürmektedirler. Dönüştürülen bu enerji taşıtın hızlanma, yavaşlama, sabit hız gibi çeşitli çalışma koşullarında ihtiyacı olan enerjiyi karşılamak için kullanılmaktadır. IYYM' de ideal yanmanın gerçekleştirilememesi sebebiyle karışımın yanması tam olarak tamamlanamamakta, atık enerji oluşmakta ve havanın kirlenmesine sebep olan $\mathrm{HC}$ ve $\mathrm{CO}$ gibi zehirleyici emisyonlar ortaya çıkmaktadır [1]. Atmosfere atılan emisyonlar insan sağlı̆̆ına zarar vermekte, sera etkisi oluşturarak küresel isınmaya neden olmakta ve dünyanın ekolojik dengesini bozarak iklim değişikliği, buzulların erimesi gibi insan yaşamı için önemli pek çok olumsuz sonuçlara sebebiyet vermektedirler [2]. Dolayısıyla yerel yönetimler için yerli, temiz ve yenilenebilir enerji kaynaklarının kullanabilmesi oldukça önemlidir. Schwarz [3]'ın araştırmasına göre yakıtın yakılmasıyla elde edilen enerjinin \% 70-80'i mekanik enerjiye dönüştürülememekte, 1sı enerjisi şeklinde motor parçalarına ve egzoz gazlarına geçmektedir. Enerjinin verimli bir șekilde dönüştürülebilmesi ya da atık enerji miktarının azaltılması IYYM' lerin verimliliği açısından oldukça önemlidir. Taşıtların verimlerini arttırmak, ürettikleri kirletici miktarlarını azaltmak amacıyla elektrikli taşıtlar, yakıt hücreli taşıtlar ve hibrit elektrikli taşıtları da kapsayan araştırma ve geliştirme çabaları hız kazanarak devam 
etmektedir [4-7]. Bu konulara paralel olarak araçlarda kullanılan bataryaların uzun ömürlü ve daha ucuz maliyete sahip üretim araştırmaları da önemli ölçüde hız kazanmıştır [8-10]. Pnömatik motorlar emme zamanında basınçlı havanın silindir içerisine verilmesi ile genişleme yaparak iş üreten makinelerdir. Sistem üzerinde 1 sıl kayıplar ve atık enerji oluşmamaktadır. $\mathrm{Bu}$ yönüyle basınçlı hava motorları yenilenebilir ve emisyonları en az düzeyde olan motorlardır. Bununla birlikte benzin veya dizel bir içten yanmalı motor, pnömatik motor ile hibrit olarak çalıştırıldığı araştırmalarda bulunmaktadır [11]. Bu çalışmalarda hedef daha verimli bir yanma ile daha az yakit tüketimidir. Günümüze kadar yapılan pnömatik motorlar üzerindeki çalışmalarda genellikle mekanik olarak havanın silindir içerisine alınması sağlanmıştır. Fakat motor üzerine yerleştirilen bu mekanik parçalar sürtünmeleri artırdığından dolayı motordan alınan güç ile birlikte sistem içerisine alınan havanın volümetrik verimi değişen yük ve motor devirlerinde düşmektedir. Volümetrik verimi artırmak için değişken supap zamanlaması uygulaması mekanik sistemlerde dar bir çalışma aralığında yapılabilmekte ve sistem karmaşık bir hal almaktadır [12]. Basınçlı hava motorları, bataryaların elektrik enerjisini kimyasal enerji olarak depolaması esası yerine "depolanan iş akışkanı" kullanarak çalışan motorlardır. Bu çalışmada havanın silindir içerisine sürülmesinde bir elektromanyetik supap kullanılmıştır. Yapılan araştırmalar sonucunda elektromanyetik supapların deneysel olarak çoğunlukla IYYM' lerde kullanıldığı görülmüştür [1315]. Ayrica elektromekanik supaplar esnek bir çalışmaya sahip olduklarından IYM' lerde değişken supap zamanlamasına da izin vermektedirler [16-19]. Bu çalışmada iki zamanlı 49cc'lik bir benzinli motor silindir kapağı üzerinde değişiklik yapılarak basınçlı hava ile çalışır duruma getirilmiştir. Emme zamanında silindir içerisine hava vermek için bir elektromanyetik emme supabı kullanılmıştır. Egzoz zamanı için motorun egzoz portu kullanılmış ancak 700 1/min motor hızından sonra yeterli boşaltmayı yapamadığ görülerek, dairesel kam milinden hareket alan bir egzoz supabı da silindir kapağı üzerine yerleştirilmiştir. Şekil 1' de tasarımı yapılan elektromanyetik supap ve silindir kapağı ile bu donanımın motor üzerine montaj resmi gösterilmiştir.

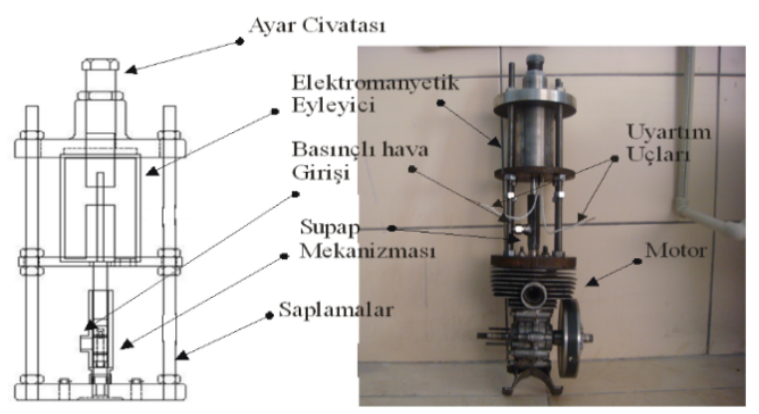

Şekil 1. Elektromanyetik supap donanımı (Electromagnetic valve equipment)
Elektromanyetik supabın çalıştırılması bir mikrodenetleyici devre kullanılarak yapılmıştır. Mikrodenetleyiciler hem hassas hem de güvenilir bir çalışma karakteristiklerine sahiptirler ve mikroişlemcilere çok benzemektedirler. Mikroişlemcili bir sistem işlemci dişında program saklamak için bellek elemanları ve dış dünyayla bağlantı kurmak için giriş/çıkış arabirim devrelerine gereksinim duyar. Mikroişlemci yalnız başına kullanılamaz [20, 21]. Mikrodenetleyicilerde çevresel arabirimler, bir tümleşik aygıt içinde birleştirildiğinden sistem hızı ve güvenilirliği artmıştır, maliyet azalmıştır. Ayrıca kullanım kolaylığı sağlanmakla birlikte karmaşık yapı ortadan kaldırılmıştır. Bu çalışmada denetleyici olarak Atmel firmasının atmega8 microdenetleyicisi kullanılmıştır. Sistemde kullanılan mikrodenetleyici devresi elektromanyetik supap eyleyicisinin kontrolünü ve böylelikle sisteme giren havanın kontrolünü yapmaktadır. Elektromanyetik eyleyici içerisinde eksenel olarak hareket eden ve manyetik alandan kolayca etkilenen bir manyetik nüve ile supabın açılmasın sağlayan supap kontrol mili bulunmaktadır. Elektromanyetik eyleyiciye enerji verildiğinde, bobin içerisinde manyetik alan meydana gelir ve içerisindeki manyetik nüveyi kendine doğru çeker. Aşağı doğru hareket eden mil bağlı olduğu hava supabının içerisinde bulunan yayı $4 \mathrm{~mm}$ kurarak supabı açar ve motorun silindirine basınçlı havanın dolmasını sağlar. Oluşan hava basıncından dolayı piston ileri doğru hareket ederek eksensel hareket meydana gelir. Enerji kesildiği anda yay, supap mili ve bağlı olduğu manyetik göbeği yukarı doğru hareket ettirir ve supabı kapatarak hava verme işlemini sona erdirir.

Elektromanyetik eyleyicinin boyutlandırılmasında analitik bir yaklaşım dikkate alınmış ve manyetik devrelerdeki kuvvetlerin bulunması için zahiri yer değişim metodu kullanılmıştır. Silindirik koordinat sisteminde üç boyutlu uzay için kuvvet Eşitlik 1 ile ifade edilebilir.

$\vec{F}=-\left(\frac{\partial W}{d \rho} \overrightarrow{\mathrm{a}}_{\rho}+\frac{1}{\rho} \frac{\partial W}{d \phi} \overrightarrow{\mathrm{a}}_{\phi}+\frac{\partial W}{d z} \overrightarrow{\mathrm{a}}_{\mathrm{z}}\right)$

Eşitlik 1'de verilen ifade elektromanyetik eyleyicinin tek boyutlu hareket yaptığından dolayı düzenlendiğinde Eşitlik.2'deki gibi yazılabilir [22].

$f_{f l d}=-\frac{(N \times i)^{2} \mu_{0} A}{2\left[x+\frac{g}{2}\right]^{2}}$

Burada, $f_{f l d}$ manyetik kuvveti (N), $N$ uyartım sargısının tur sayısını, $\mu_{0}$ boşluğun manyetik geçirgenliğini, $A$ hava aralığının kesiti $\left(\mathrm{m}^{2}\right), x$ hava aralığının uzunluğu $(\mathrm{m}), g$ yan hava aralığının 

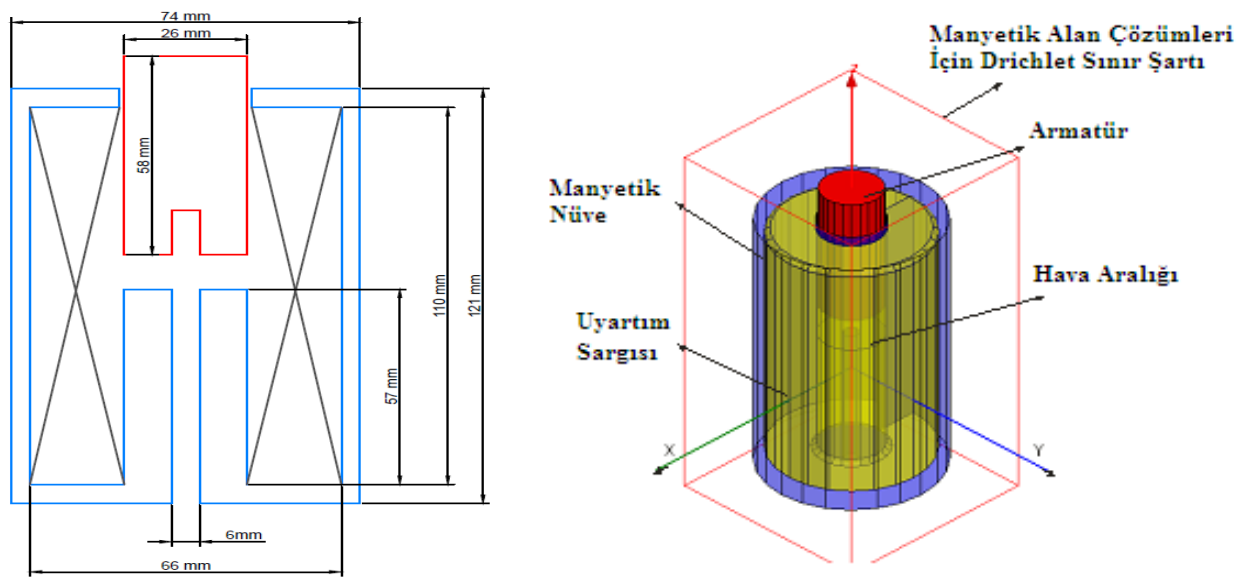

Şekil 2. Elektromanyetik eyleyici (Electromagnetic actuator)

uzunluğu (m), $i$ sargı akımını (A) göstermektedir. Elektromanyetik eyleyicinin içyapısı 2 boyutlu ve 3 boyutlu olarak Şekil 2'de gösterilmiştir. Elektromanyetik eyleyicinin analitik ve sonlu elemanlar metodu (Ansoft Maxwell 2D) ile tahmin edilen tasarımın elektriksel ve manyetik büyüklükleri hesaplanmış, sonuçlar prototip ile karşılaştırılmıştır. Tepki süresinin hesaplanabilmesi için anlık simülasyonlar yapılmıştır [23].

\section{ELEKTROMANYETIK SUBAP KONTROL SISTEMININ TASARIMI VE UYGULAMASI (ELECTROMAGNETIC VALVE CONTROL SYSTEM DESIGN AND IMPLEMENTATION)}

$\mathrm{Bu}$ çalışmada, denetleyici tabanlı programlanabilir pnömatik motor kontrol ünitesi tasarlanmış ve uygulaması yapılmıştır. Şekil 3'de kontrol ünitesinin blok diyagramı verilmiştir. İstenilen emme zamanı parametresi kontrol sistemi ile butonlar yardımıyla ayarlanabilmektedir.

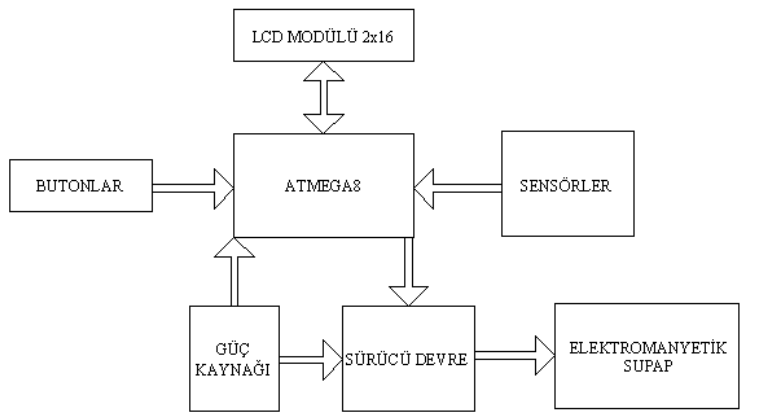

Şekil 3. Kontrol ünitesinin blok diyagramı (Block diagram of the control unit)

Uygulaması yapılan kontrol sisteminin özelliği motorun emme zamanı için kullanılan krank mili cinsinden açı değerinin sistem başlatılmadan önce $5^{\circ}$ 'lik açı aralıkları ile hassas bir şekilde ayarlamasıdır. Denetleyici ayrica LCD ekranda dakikadaki hız bilgisini de görüntüler. Böylelikle kullanıcı motorun hızı hakkında bilgi sahibi olabilir.
Motorun aşırı yüklenerek durması gibi durumlarda denetleyici bu durumu algilayarak kontrol algoritmasinı durdurur ve kullanıcıya LCD ekranda uyar1 mesaj1 verir. Sistemde kullanılan Atmega8 8kb hafizaya sahip 16Mips işlem (saniyede 16 milyon işlem) yapabilen 8 bit mikro denetleyicidir. Sistemde bu denetleyicinin seçilmesinin sebebi, yüksek hızlı işlem yapabilmesi, manyetik gürültülerden (elektromanyetik eyleyicinin açılma ve kapanma anındaki gürültüleri) muadillerine nazaran daha az etkilenmesidir. Şekil 4'de Atmega8 mikrodenetleyicisinin pin görünüşü verilmiştir.

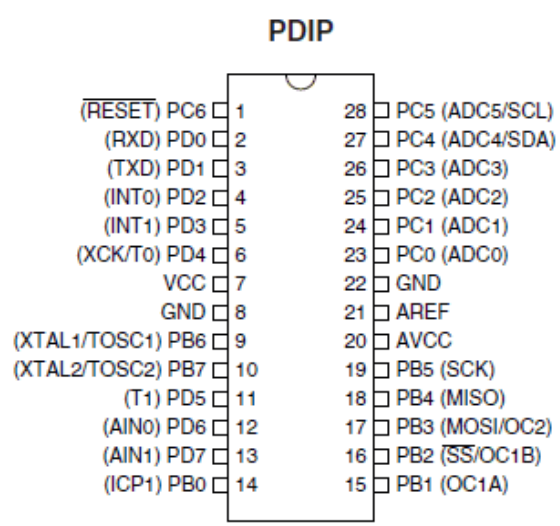

Şekil 4. Mikrodenetleyisinin giriş ve çıkışları (Inputs and outputs of microcontroller)

Atmega8 mikrodenetleyicisi MCS-51 ailesine aittir. Mikrodenetleyici tabanlı kontrol kartına sanayi otomasyonuna yönelik küçük boy bilgisayar özelliği kazandırmaya imkan sağlayan özellikler sadece bir çip içerisinde yer almaktadır [24]. Pnömatik motorun çalışma sıcaklığı, havanın içeriye hangi zamanlarda sürüleceği, ve motorun hızı gibi büyüklükleri sensörlerden alarak işleyecek olan mikrodenetleyici çalışma şartlarını optimum bölgede tutmaktadır. Motor hızını ölçmek ve supapların açılıp kapanma zamanlarının tespitini yapmak için CNY 70 olarak isimlendirilen içerisinde bir adet transistör ve bir adet 1şık yayan kaynak bulunan sensör kullanılmıştır [25]. 
Elektromanyetik supapta kullanılan bobindeki sıcaklığın ve motorun çalışma sıcaklığının ölçümü için National firması tarafindan üretilen LM35 isimli sensör kullanılmıştır [26]. Bu sensör, $-55^{\circ} \mathrm{C}$ ile $+150^{\circ} \mathrm{C}$ arasındaki sıcaklıkları ölçer ve son derece doğrusal bir karakteristiğe sahiptir. Devrede kullanılan likit kristal ekran (LCD), kontrolörü aynı zamanda karakter Üretici RAM (CGRAM) olarak adlandirılan ve kullanıcı tarafindan tanımlanabilen 8 karakter içeren bir hafizaya sahiptir.

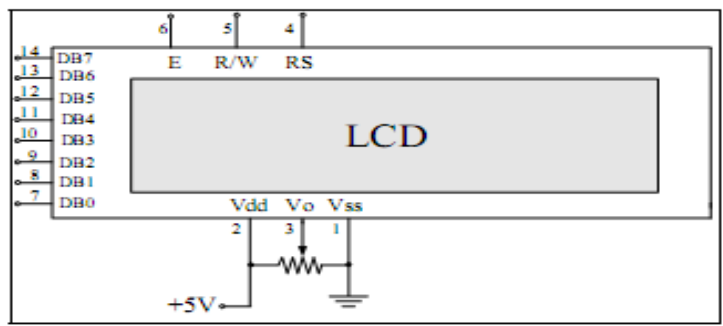

Şekil 5. LCD blok șeması (Block diagram of the LCD)

Aktifleşme ucu (E) bütün LCD işlemlerinde gereken ana kontrol hattıdır. Her bit işlem RS ve $R \backslash W$ hatlarının durumlarını belirler. Eğer yapılan işlem, bir komutun veya bir verinin LCD'ye yazılması ise veri LCD veri yoluna yerleştirilir ve bu anda aktifleme hattı darbesi gönderilir. $\mathrm{Bu}$ darbe 0-1-0 şeklinde pozitif darbedir. LCD, blok şeması Şekil 5'de özetlenmiştir [27]. Sürücü devrede International Rectifier firması tarafindan geliştirilen IRFP064N isimli mosfet kullanılmıştır [28]. Bu hızlı transistör 55 Volt ve 110Amper akımı anahtarlama yapabilecek özelliktedir ve $175^{\circ} \mathrm{C}$ sıcaklıklarda çalışabilmektedir. Mosfetin iç direnci $0,008 \Omega$ gibi düşük bir değere sahiptir.

\section{SİSTEMIN ÇALIŞMASI (SYSTEM STUDY)}

Pnömatik motorun en iyi çalıșma performansını araştırılması açısından Emme supabı kapanma gecikmesi (EmKG) $40^{\circ}, 50^{\circ}, 60^{\circ}$ ve $70^{\circ}$ olmak üzere 4 farklı supap zamanlaması denenmiştir. Hava tüketim debisi, motor gücü ve motor momenti açısından en iyi performans değerleri EmKG $60^{\circ}$ ' de elde edilmiştir. Pnömatik motorun çalıştırılmasında bu değer esas alınmıştır. Şekil 6' da 20 bar çalışma basıncı EmKG $40^{\circ}$ EmKG 50 , EmKG $60^{\circ}$ ve EmKG $70^{\circ}$ emme supap zamanlaması, sabit gaz kelebek açıklığı şartlarında motor momentinin, hava tüketim debisinin ve motor gücünün motor hızına göre değişsimi verilmiştir. Grafiklerden anlaşıldığı üzere maksimum momentin elde edildiği bölgede hava tüketimi de en üst seviyeye ulaşmaktadır. $\mathrm{Bu}$ durum hemen hemen bütün emme supap zamanlamasında benzerlik göstermektedir. EmKG $40^{\circ}$ 'den itibaren EmKG $70^{\circ}$ 'ye kadar motor momenti 800 1/min motor devrine yakın bölgelerde artış göstermektedir. Ancak Emkg $70^{\circ}$ 'de emme supabının fazla açık bırakılması ve içerideki egzoz yapılması gereken havanın dışarı atılması için yeterli zamanın bulunmaması sebebiyle negatif işin oluşması motor momentini EmKG 70' de düşürmüştür. Dolayısıyla pnömatik motorun çalıştırılmasında emme supap zamanlaması olarak EmKG $60^{\circ}$ seçilmiştir. Pnömatik motorun çalıştırılması için mikrodenetleyici, motor volanına yerleştirilmiş olan sensör ile üst ölü noktayı (ÜÖN) referans olarak alır ve buradan itibaren silindir içerisine sürülmesi düşünülen KMA'sı cinsinde dereceyi hesaplar. Motor çalıştırılmak istendiğinde denetleyici başlangıçta elektromanyetik supaba (ÜÖN)' dan itibaren 10 defa $30 \mathrm{~ms}$ sabit sürede yol verir. Böylece motorun ilk hareketi sağlanmış olur. Motor $100 \mathrm{~d} / \mathrm{d}$ hıza ulaştıktan sonra denetleyici volana bağlı sensörden motorun konum ve hiz bilgisini okur. Denetleyici $360^{\circ}$ lik tam devir açısının ilk $60^{\circ}$ ' sinde elektromanyetik supaba enerji vererek motora hava girişini sağlar. $60^{\circ}$ 'nin sonunda elektromanyetik supabın enerjisi denetleyici tarafindan kesilir. Böylece (ÜÖN)' dan itibaren $60^{\circ}$ pnömatik motora basınçlı hava girişi sağlanır ve geri kalan $300^{\circ}$ ' de motor genişleme ve egzoz zamanını yapar. Şekil 7'de pnömatik motor, mikrodenetleyici ve sürücü devresinin çalışma sistemi şematik olarak gösterilmiştir.
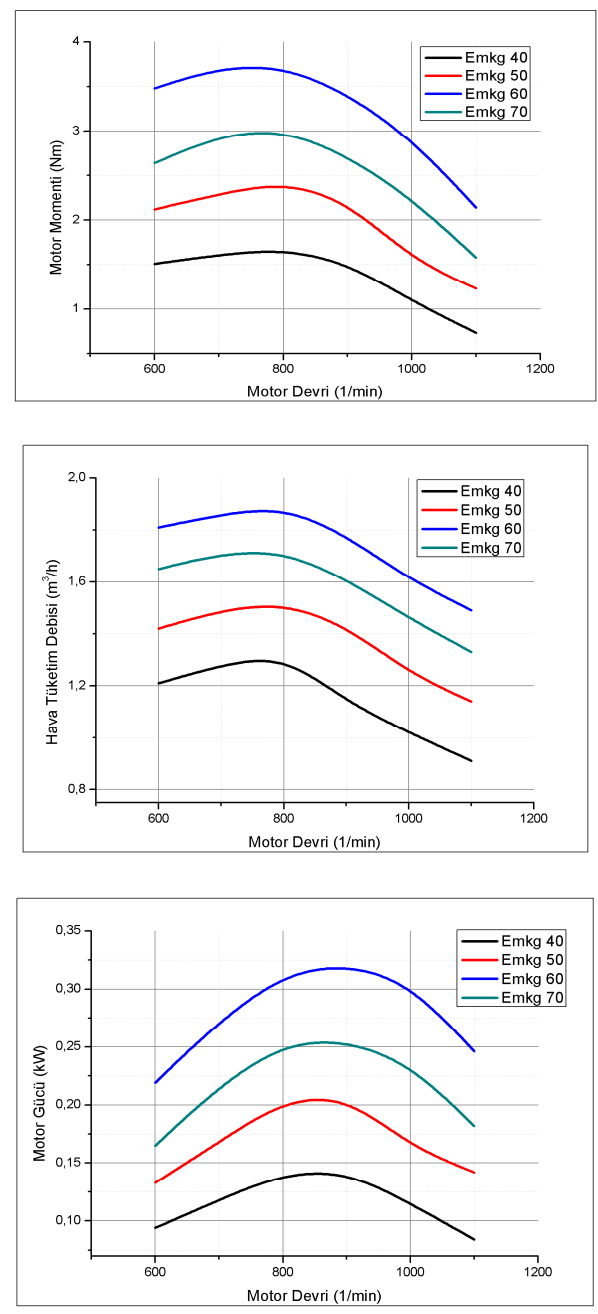

Şekil 6. Motor performans eğrileri (Engine performance curves) 


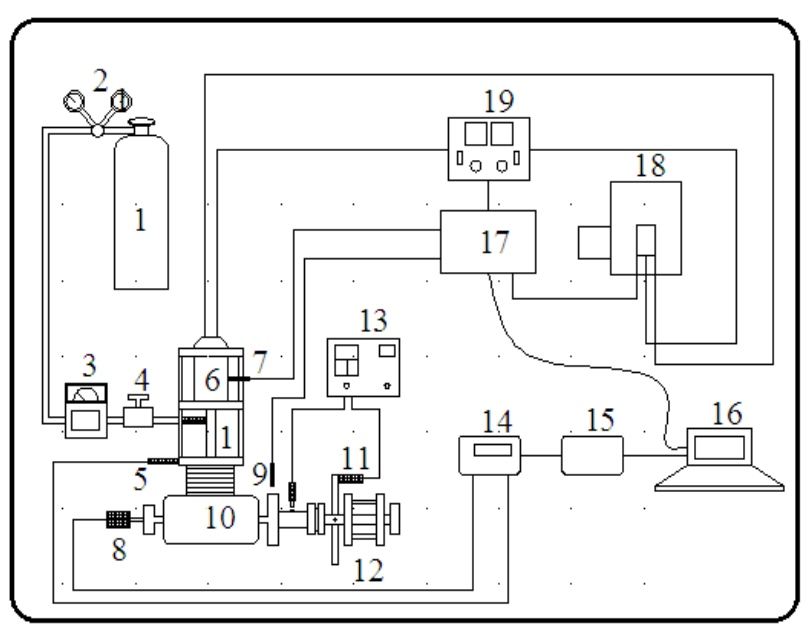

Şekil 7. Pnömatik motor, mikrodenetleyici ve sürücü devresinin çalışma sistemi şeması (Operation diagram of the pneumatic engine, microcontroller, and the driver circuit) (1. Basınçlı hava tankı, 2. Basınç regülâtörü, 3. Akış ölçer, 4. Akış kontrol valfi, 5. Silindir içi anlık basınç sensörü, 6. Elektromanyetik bobin, 7. LM35 sıcaklık sensörü, 8. Enkoder, 9. CNY70, 10. Basınçlı hava motoru, 11. Yük hücresi, 12. Dinamometre, 13. Gösterge paneli, 14. Amplifikatör, 15. Veri toplama kart1, 16. Bilgisayar, 17. Kontrol devresi, 18. Sürücü devre, 19. DC güç kaynağı)

Motor hızı $600 \mathrm{~d} / \mathrm{d}$ için 1 saniyedeki devir $=600 / 60=$ $10 \mathrm{~d} / \mathrm{s}$ olur. 1 tur $1 / 10=100 \mathrm{~ms}$ sürer. Denetleyici referans noktasından itibaren motora $100 \mathrm{x}(60 / 360)=$ $16,67 \mathrm{~ms}$ boyunca hava girișini sağlar. Değișen motor hızlarında yine aynı hesaplama yöntemi kullanılarak motora sürekli $60^{\circ}$ lik hava girişi sağlanmaktadır.

\section{YAZILIM (SOFTWARE)}

Sistemde kullanılan Atmega8 mikrodenetleyicisinin yazılımı, yüksek seviyeli ve ücretsiz bir C derleyicisi olan WINAVR programı ile yazılmıştır. Sistemdeki Atmega8 mikrodenetleyicisi $16 \mathrm{MHz}$ lik clock sinyali ile çalıştırılmaktadır. Bu sayede saniyede 16 milyon işlem yapabilmekte ve sistemin kontrolü hızlı bir şekilde sağlanabilmektedir. Sisteme enerji verildiğinde öncelikle programda kullanılan değişkenlere gerekli değerler yüklenir. Sistem çalışmaya başladığında elektromanyetik supap enerjilendirilir ve motora hava girişine müsaade edilir. $\mathrm{Bu}$ esnada açı hesaplanmaz ve supap $30 \mathrm{~ms}$ enerjili bırakı1ır. Motor henüz yol alma aşamasında olduğu için ilk 10 devirde 60 derecelik açı aranmaz. İlk 10 devrin ardından artık motor yol almıştır. Onuncu yol vermede volanın referans noktasından ayrılip tekrar referans noktasina gelmesindeki süre denetleyicin donanımsal zamanlayıcıları tarafindan hesaplanır. Sensörün referans noktasına gelmesi beklenir ki bu süre yaklaşık en fazla $40 \mathrm{~ms}$ civarındadır. Sensör referans noktasına geldikten sonra elektromanyatik supap enerjilendirilir ve hesaplanan süre açı bilgisine dönüştürülür. 60 derecelik açı kadar yol kat edildiğinde elektromanyetik supabın enerjisi kesilir. Yine aynı şekilde hesaplanan süre hız bilgisine dönüştürülerek motor hızı LCD ekranda görüntülenir. Sensörün referans noktasından ayrilıp tekrar referans noktasına gelmesi $35 \mathrm{~ms}$ ise; Devir sayıs1 $=(1 / \mathrm{t}) \times 60$ eşitliği ile bulunur. Böylece verilen $35 \mathrm{~ms}$ örneği için $(1 / 35 \mathrm{e}-3) \times 60=1714 \mathrm{~d} / \mathrm{d}$ olarak motor devri hesaplanır ve LCD ekranında görüntülenir. Sensör tekrar referans noktasına geldikten sonra işlemler yine aynı şekilde tekrar edilerek motora sürekli 60 derecelik hava girişi sağlanır. Motor, aşırı yük gibi herhangi bir sebeple durursa bu durum denetleyici tarafindan algilanır. Elektromanyetik supap tamamen devreden çıkartılır. Aynı şekilde elektromanyetik eyleyicinin sıcaklığının aşırı yükselmesi LM35 sıcaklık sensörü vasıtası ile denetleyici tarafindan algılanır ve elektromanyetik eyleyicinin zarar görmemesi için motor durdurulur. Yazılıma ait akış diyagramı Şekil 8'de verilmiş olup, koruma sistemleri donanımsal kesme rutinleri tarafindan icra edildiği için verilen akış diyagramında gösterilmemiştir.

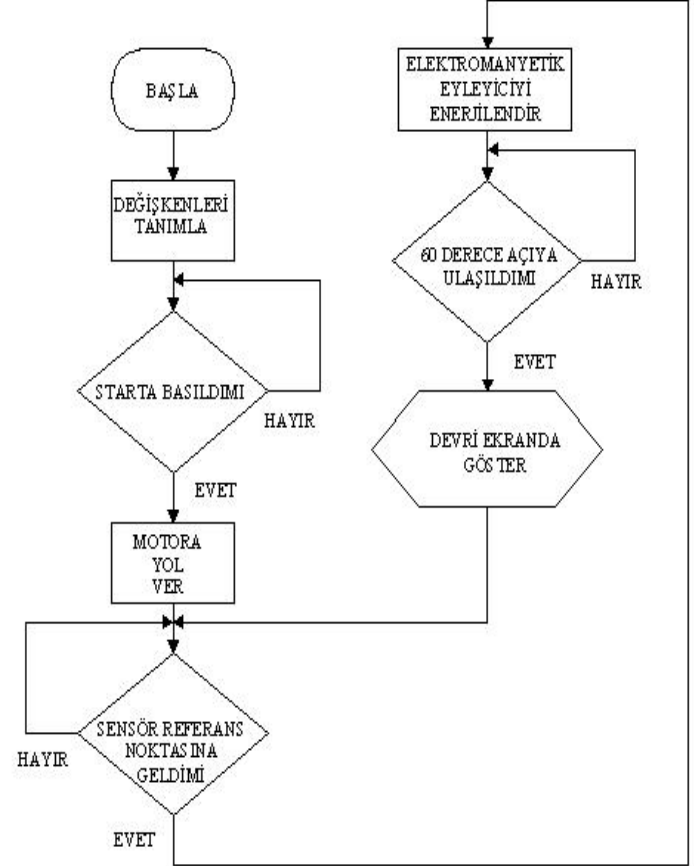

Şekil 8. Sistemin akış diyagramı (Flowchart of the system) 


\section{ELEKTROMANYETIK CALISTIRILMASI VE}

Elektromanyetik supabın enerjilendirilmesi ve çalışma basıncına bağlı olarak ulaşılabilen en yüksek motor hızı yaklaşık 1612 1/min olmuştur. Dolayısıyla elektromanyetik supap en verimli emme supap zamanlaması olan $60^{\circ}$ ' de bu hıza ulaşırken kontrol ünitesi her devirde 6,2 ms'lik bir enerjilendirme süresini sağlayabilmiştir. Yapılan uygulamada, alınan ekran görüntüsü Şekil 9'da verilmiştir.

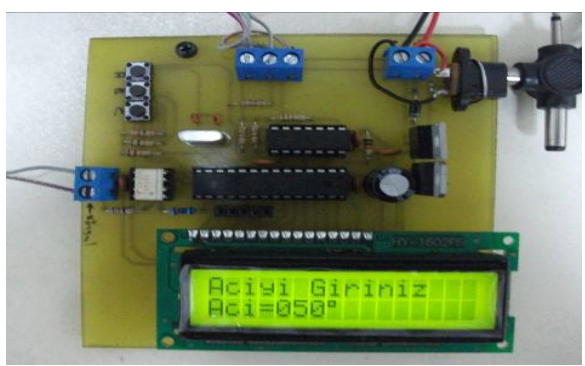

Şekil 9. LCD ekran görüntüsü (LCD screen display)

Şekil 10'da elektromanyetik eyleyicinin açılması esnasında armatür boyunun çekilen akım ile ilişkisi gösterilmektedir. Burada elektromanyetik eyleyicinin $4 \mathrm{~mm}$ mesafede yaklaşık olarak $6,2 \mathrm{~ms}$ sürede açıldı̆̆ gözlemlenmektedir.

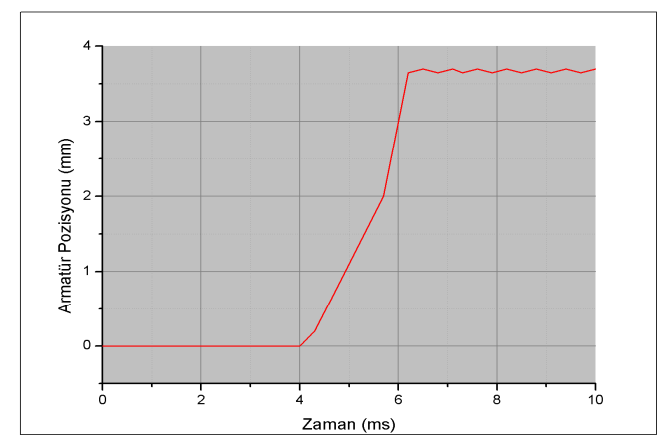

Şekil 10. Elektromanyetik eyleyicinin çektiği akım ve armatürün pozisyonun zamana göre değişimi (Variation according to time the armature position with current taken by electromagnetic actuator)

Motorun en verimli çalışma basıncı olan 20 bar çalışma basıncı ve Emkg $60^{\circ}$ ' de elde edilen motor performans değerleri Şekil 11'de verilmiştir. Motor momenti hava tüketiminin maksimum olduğu bölgededir. Motor devrinin artmasıyla motor içindeki sürtünmelerin artması ve içeriye alınan havanın boşaltılmasına yeteri kadar zamanın olmaması motor momentinin ve gücünün düşmesine sebep olmaktadır. Hava tüketim debisi elektromanyetik supabın açık kalma süresi ile doğru orantılıdır ve motor verimine doğrudan etki etmektedir. Çünkü kullanılan basınçlı hava daha önceden sıkıştırıldığı için hava tüketimi arttıkça havayı sıkıştırmakta kullanılan enerjide $\left(\mathrm{W}_{\mathrm{c}}\right)$ artmaktadır. Başka bir deyişle elektromanyetik supabın açık kalma süresi uzatılırsa verim değeri de o kadar düşmektedir. Verime etki eden bir diğer parametre elektromanyetik supabın tüketmiş olduğu elektrik enerjisidir ( $\left.\mathrm{W}_{\mathrm{EMS}}\right)$. Eşitlik 3'de motor verimine etki eden parametreler gösterilmiştir. Elektromanyetik supabın çevrim başına tükettiği enerji, 1 saniyede tükettiği enerji ile bir çevrimde elektromanyetik supabın enerjilendirildiği sürenin (ÇES) çarpılmasılyla bulunur;

$W_{E M S}=$ ÇES.I.V

Basınçlı hava motorlarının verimi Eşitlik 4'de ifade edildiği gibi sistemden alınan işin $\left(\mathrm{W}_{\text {net }}\right)$, basınçlı havanın sıkıştırmasında kullanılan iş $\left(\mathrm{W}_{\mathrm{c}}\right)$ ile elektromanyetik supabın tükettiği enerjinin ( $\left.\mathrm{W}_{\mathrm{EMS}}\right)$ toplamına oranı olarak ifade edilebilir.

$\eta_{\mathrm{BHM}}=\frac{\mathrm{w}_{\text {net }}}{\mathrm{w}_{\mathrm{c}}+\mathrm{w}_{\mathrm{EMS}}}$
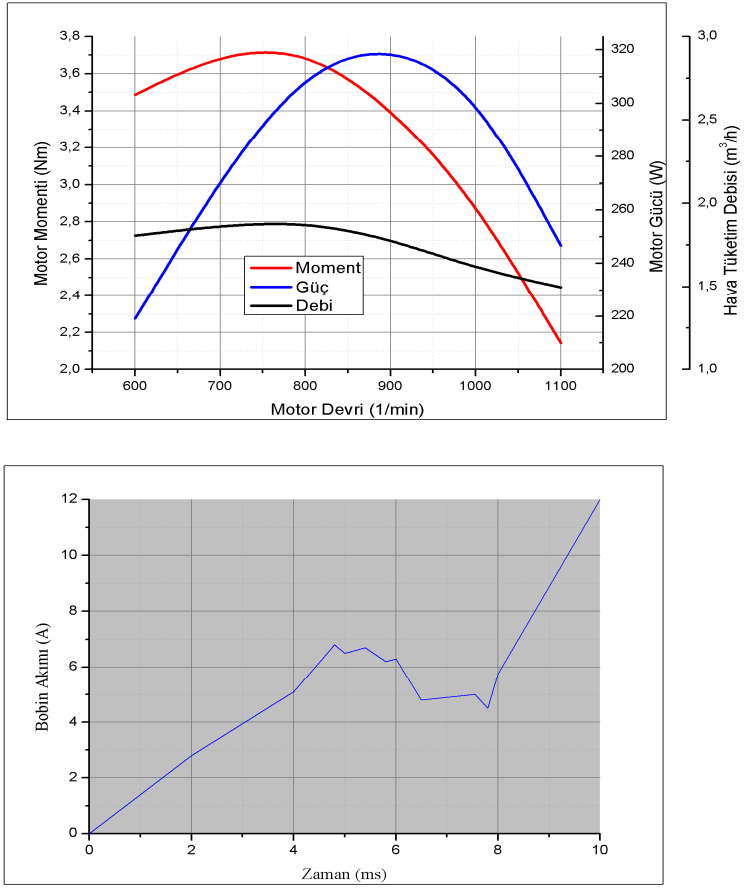

Şekil 11. Motorun performans karakteristikleri (The performance characteristics of engine)

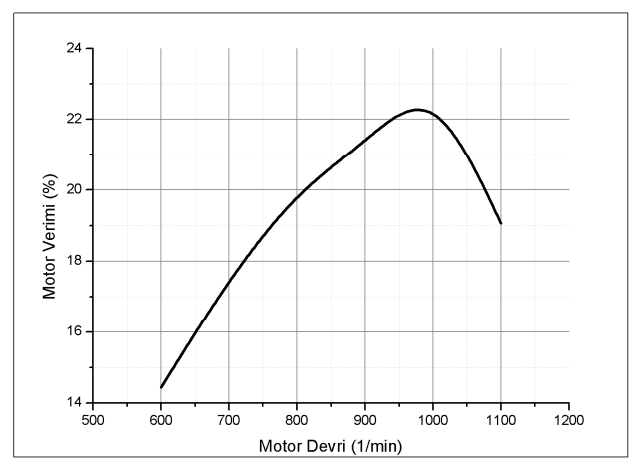

Şekil 12. Motor veriminin motor hızına göre değişiminin gösterilmesi (Showing the efficiency of Engine variation with engine speed) 
Şekil 12'de emme supap zamanlaması $60^{\circ}$ 'de ve 20 bar çalışma basıncında motor veriminin motor hızına göre değişimi görülmektedir. Bu grafikte, 1000 1/min motor hızına kadar motor veriminin arttığı ve bu hızdan itibaren verimin düştüğü görülmektedir. Motor hızına bağlı olarak içeriye alınan havanın miktarının artması ve elektromanyetik supapta tüketilen enerjinin artması motor veriminin düşürmüştür.

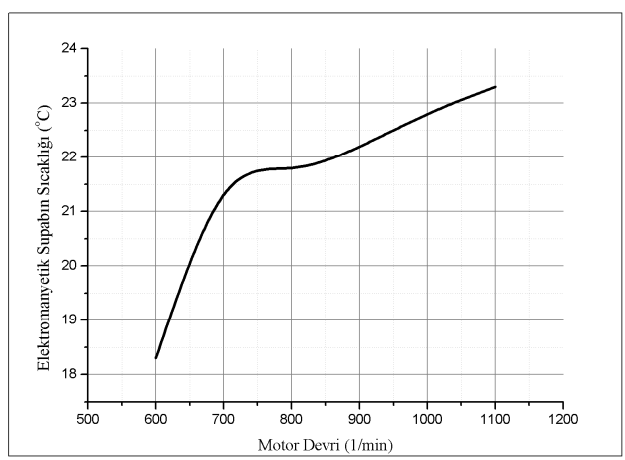

Şekil 13. Elektromanyetik supap sıcaklığı (Electromagnetic valve temperature)

Şekil 13'de elektromanyetik supabın motor devrine bağlı olarak sıcaklığının değişimi gösterilmektedir. Grafiğe göre motor devri arttıkça elektromanyetik supabın çekirdeğinde ve sargılarında, sıcaklığın arttığ gözlemlenmektedir. Buna, motor hızının artmasıyla supap mekanizmasının daha hızlı çalışması ve sürtünmelerin artması sebep olmaktadır. Uzun süreli çalışmalarda ilave bir soğutma düzeneği ile supap mekanizmasının soğutulması gerekmektedir.

\section{SONUÇLAR (CONCLUSIONS)}

Bu çalışmada Atmega8 mikrodenetleyici kullanılarak, basınçlı hava ile pnömatik olarak çalışır hale dönüştürülmüş benzinli ve iki zamanlı bir motorun kontrol devresi yapılmıştır. Yapılan testlerde 8 bar basınçlı hava ve elektromanyetik supap içerisinde ise $1,7 \mathrm{~mm}$ tel çapına ve 550 amper tura sahip bobin kullanılmıştır. Elektromanyetik supap 12 Volt gerilim ile çalıştırılmış ve 8 Amper akım çekmiştir. $\mathrm{Bu}$ şartlarda motorun $450 \mathrm{~d} / \mathrm{d}$ hıza ulaştığ1 görülmüştür. Daha sonra motor 20 bar basınç ve aynı eyleyici 24 Volt gerilim ile çalıştırılmış ve 12,5 Amper akım çekmiş ve bu şartlarda motorun $1612 \mathrm{~d} / \mathrm{d}$ hıza ulaşmıştır. Yapılan kontrol devresi bu motor hızında elektromanyetik supabı 6,2 ms sürede açma ve kapama işlemini gerçekleştirebilmiştir. Ölçülen değerler incelendiğinde, en verimli motor hızının ulaşılan en yüksek hız olmadığı ve yaklaşık olarak 1000 1/min olduğu ortaya çıkmıştır. $\mathrm{Bu}$ yönüyle, tasarlanan kontrol ünitesi ile çalıştırılan deney motoru, içten yanmalı motorlara benzerlik göstermektedir. Daha az hava tüketimi sağlamak amaciyla elektronik kontrol devresi değişken supap zamanlamasına uyarlanabilir. Basınçlı hava motorları yüksek torkları düşük devirlerde üretebilen motorlardır. $\mathrm{Bu}$ yönleriyle gelecekte alternatif bir motor özelliği taşımaktadırlar. Özellikle depolanması güç olan elektrik enerjisi basınçlı havayı sıkıştırmakta kullanılıp yeraltı tesislerde depolanabilir. Dolayısıyla gelecekte olası bir elektrik enerjisi problemi esnasında alternatörleri çevirmek için basınçlı hava motorları kullanılıp tekrar elektrik enerjisi üretilebilir.

\section{KAYNAKLAR (REFERENCES)}

1. Heywood, J. B., Internal Combustion Engine Fundamentals, McGraw Hill İnc. ISBN 0-07028637-X, New York, 1988.

2. İstanbul Ticaret Odası, Rüzgar Enerjisi, Su Matbaacılik, İstanbul, 2001.

3. Schwarz, M., Getting There from Here. Environmental and Safety Engineering, Ford Motor Company, USA, 1997.

4. Maggetto, G., Van, M.J., Vrije U., "Electric and Electric Hybrid Vehicle Technology: a Survey", IEE Electric, Cilt 1, No 1, 111, 2000.

5. Dawood, V., Emadi, A., "Performance and Fuel Economy Comparative Analysis of Conventional, Hybrid, and Fuel Cell Heavy-Duty Transit Buses", IEEE 58th Vehicular Technology Conference, Cilt 5, 3310- 3315, 6-9 Ekim 2003.

6. Tyrus, J.M., Long, R.M., Kramskaya, M., Fertman, Y., Emadi, A., "Hybrid Electric Sport Utility Vehicles", IEEE Transactions on Vehicular Technology, Cilt 53, 1607-1622, 2004.

7. Ravindra, P.J., Anil, P.D., "Hybrid Electric Vehicles:The Next Generation Automobile Revolution", ICEHV 06th. IEEE Conference, Pune, 1-6, 18-20 Aralık 2006.

8. Scott, B.P., Whitacre, J.F., Jay, Apt., "The economics of using plug-in hybrid electric vehicle battery packs for grid storage", Journal of Power Source, Cilt 195, No 8, 2377-2384, 2010.

9. Mesbahi, T., Khenfri, F., Rizoug, N., Chaaban, K., Bartholomeüs, P., Le Moigne, P., "Dynamical modeling of Li-ion batteries for electric vehicle applications based on hybrid Particle SwarmNelder-Mead (PSO-NM) optimization algorithm", Electric Power Systems Research, Cilt 131, 195-204, 2015.

10. Jaguemont, J., Boulon, L., Dube, Y., "A comprehensive review of lithium-ion batteries used in hybrid and electric vehicles at cold temperatures", Applied Energy, Cilt 164, 99$114,2016$.

11. Dimitrova, Z., Marechal, F., "Gasoline hybrid pneumatic engine for efficient vehicle powertrain hybridization", Applied Energy, Cilt 151, 168177, 2015.

12. Xie, H., Song, K., He, Y., "A hybrid disturbance rejection control solution for variable valve timing system of gasoline engines", ISA Transactions, Cilt 53, No 4, 889-898, 2014. 
13. Chladny, R.R., Koch, C.R. and Lynch, A.F., "Modeling Automotive Gas-Exchange Solenoid Valve Actuators", IEEE Transactions on Magnetics, Cilt 41, No 3, 1155-1162, 2005.

14. Chang, W.S., Parlikar, T.A., Seman, M.D., Perreault, D.J., Kassakian, J.G. and Keim, T.A., "A New Electromagnetic Valve Actuator, Power Electronics in Transportation", IEEE Power Electronics in Transportation, ISBN 0-78037492-4, 109-118, 2002.

15. Clark, R.E., Jewell, G.W., Forrest, S.J., Rens, J. and Maerky, C., "Design Features for Enhancing the Performance of Electromagnetic Valve Actuation Systems", IEEE Transactions on Magnetics, Cilt 41, No 3, 1163-1168, 2005.

16. Giglio, V., Iorio, B., Police, G. and Gaeta, A., "Analysis of Advantages and of Problems of Electromechanical Valve Actuators, Variable Valve Actuation", SAE, 2002-01-1105, 2002.

17. Park, S.H., Lee, J., Yoo, J. and Kim, D., "A Study on the Design of Electromagnetic Valve Actuator for VVT Engine", KSME International Journal, Cilt 17, No 3, 357-369, 2003.

18. Wang Y., Megli, T. and Haghgooie, M., "Modeling and Control of Electromechanical Valve Actuator, Variable Valve Actuation", SAE, 2002-01-1106, 2002.

19. Kamış, Z., Yüksel, İ., “An Investıgatıon of Effect of Applied Electrical Voltage on System Dynamic Behavior and Energy Consumption of an Electromechanical Valve Actuator", Journal of the Faculty of Engineering and Architecture of Gazi University, Cilt 17, No 3, 161-177, 2004.

20. Bayındır, R., Kaplan, O., "PIC Denetimli Reaktif Güç Rölesi Tasarımı", Journal of the Faculty of Engineering and Architecture of Gazi University, Cilt 22, No 1, 47-56, 2007.

21. Sefa, İ., Kahraman, H.T., "Klimalar İçin Yeni Bir Kontrol Sistemi", Journal of the Faculty of Engineering and Architecture of Gazi University, Cilt 22, No 3, 339-347, 2007.

22. Guru, B., Hızıroğlu, H. R., Electric Machinery and Transformers, Oxford University Press, Michigan, USA, 1995.

23. Koca, A., Bayındır, R., Güneş, H., Kunt, M.A., Sakar, S., "Basınçlı hava motorlarında supap mekanizması için elektromanyetik eyleyici tasarımı ve uygulaması", Journal of the Faculty of Engineering and Architecture of Gazi University, Cilt 26, No 1, 73-79, 2011.

24. Internet: Atmega8.pdf, www.atmel.com /dyn/products/datasheets.asp, 2010.

25. İnternet: Cny70.pdf, http://www.vishay.com/docs /83751/cny70.pdf, 2008.

26. İnternet: Alldatasheet.com, http: //www.alldatasheet.com/view.jsp?Searchword $=\mathrm{L}$ M35, 1994.

27. Şahin, H., Dayanık, A., Altınbaşak, C., Pic Programlama Teknikleri ve Pic16F877, Atlaş Yayıncılık, İstanbul, 2006.

28. İnternet: irfp064n.pdf, www.irf.com/product info/datasheets/data/irfp064n.pdf, 1997. 